\title{
The Effect of Simvastatin on mRNA Expression of Transforming Growth Factor- $\beta 1$, Bone Morphogenetic Protein-2 and Vascular Endothelial Growth Factor in Tooth Extraction Socket
}

\author{
Chang Liu ${ }^{1}$, Zhe $\mathrm{Wu}^{2}$, Hong-chen Sun ${ }^{3 *}$ \\ ${ }^{1}$ Department of Orthodontics, School of Stomatology, Jilin University, Changchun, China \\ ${ }^{2}$ Department of Prosthodontics, School of Stomatology, Jilin University, Changchun, China \\ ${ }^{3}$ Department of Oral Pathology, School of Stomatology, Jilin University, Changchun, China
}

\begin{abstract}
Chang Liu, Zhe Wu, Hong-chen Sun. The Effect of Simvastatin on mRNA Expression of Transforming Growth Factor- $\beta 1$, Bone Morphogenetic Protein-2 and Vascular Endothelial Growth Factor in Tooth Extraction Socket. International Journal of Oral Science, 1(2): 90-98, 2009
\end{abstract}

\begin{abstract}
Aim To determine the effect of local simvastatin application on the mRNA expression level of transforming growth factor- $\beta 1$ (TGF- $\beta 1$ ), bone morphogenetic protein-2 (BMP-2) and vascular endothelial growth factor (VEGF) in the tooth sockets of rat.
\end{abstract}

Methodology Forty-eight male Wistar rats were randomly divided into experimental and control groups $(n=24)$. Polylactic acid/polyglycolic acid copolymer carriers, with or without simvastatin, were implanted into extraction sockets of right mandibular incisors. The expression of TGF- $\beta 1$, BMP-2 and VEGF mRNA was determined by in situ hybridization in the tooth extraction socket at five days, one week, two weeks and four weeks after implantation.

Results The fusiform stroma cells in the tooth extraction socket began to express TGF- $\beta 1$, BMP-2 and VEGF mRNA in both experimental and control groups from one week after tooth extraction until the end of experiment. The expression of TGF- $\beta 1$ and BMP- 2 mRNA in the experimental group was significantly up-regulated after one, two and four weeks, and expression of VEGF mRNA was significantly increased after one and two weeks compared with that in the control group.

Conclusion The findings indicate that local administration of simvastatin can influence alveolar bone remodeling by regulating the expression of a school of growth factors which are crucial to osteogenesis in the tooth extraction socket.

Keywords bone morphogenetic protein-2 (BMP-2), in situ hybridization, simvastatin, tooth extraction socket, transforming growth factor- $\beta 1$ (TGF- $\beta 1$ ), vascular endothelial growth factor (VEGF)

Document code: A CLC number: Q591.2 Received Nov. 20, 2008; Revision accepted Jan. 19, 2009

\section{Introduction}

Hydroxymethylglutaryl-coenzyme A (HMG-CoA) reductase inhibitors or statins have proved useful for the treatment of hypercholesterolemia, an essential risk factor of atherosclerosis. The beneficial effects of statins are believed to result from their ability to suppress cholesterol biosynthesis and from pleiotropic actions such as anti-inflammatory and anti-oxidant effects (Davignon, 2004). With respect to bone metabolism, simvastatin has been found to stimulate bone formation by its anabolic effect. Mundy et al. first reported that statins can stimulate new bone formation in rodents and concluded that this effect can be ascribed to an increased expression level of bone morphogenetic protein-2 (BMP-2) in bone cells. Our previous study demonstrated that local administration of simvastain carried by polylactide-coglycolide (PLGA) can reserve the height of the residual alveolar 
ridge and enhance bone mineral density (BMD) in tooth extraction sockets by increasing new local bone formation ( $\mathrm{Wu}$ et al., 2008). Some other studies suggested also that simvastatin mixed with various carriers can significantly accelerate the healing process of bone defects in rats through a higher amount of bone formation (Wong and Rabie, 2005; Ozeç et al., 2007).

The formation and remodeling of bone structures result from coupling subsequent deposition of bone matrix by osteoblasts with balanced bone resorption by activated osteoclasts. It has been reported that statins can inhibit bone resorption in vitro through suppression of the mevalonate pathway by blocking the prenylation of certain signaling molecules which are essential to osteoclast activity (Staal et al., 2003). However, some in vitro studies demonstrated that statins promote osteoblastic differentiation and mineralization by mediating the expression of various growth factors critical to the regulation of osteoblast function, and enhance the production of bone matrix protein (Mundy et al., 1999; Maeda et al., 2003; Maeda et al., 2004; Ruiz-Gaspa et al., 2007). In osteoblastic cell lines, it was found that statins increased the expression level of BMP-2 and vascular endothelial growth factor (VEGF) to accelerate osteoblast differentiation and also increased the expression of osteogenic markers, such as alkaline phosphatase (ALP), osteopontin, type I collagen, bone sialoprotein, and osteocalcin, to promote new bone formation. However, the mechanism by which statins promote new bone formation in vivo has been less well studied. It has been suggested from an immunohistochemistry study that local administration of statins triggers the early expression of VEGF and BMP-2 in parietal bone defects (Wong and Rabie, 2005).

Both BMP-2 and transforming growth factor- $\beta 1$ (TGF- $\beta 1$ ), members of the TGF- $\beta$ superfamily, have been recognized as competent growth factors that induce the differentiation of mesenchymal cells towards cells of osteoblastic linage by promoting Run2 expression in vitro (Lee et al., 2000). TGF- $\beta_{1}$ was found to promote the proliferation and early stages of differentiation of mesenchymal cells, whereas, BMP-2 can regulate the whole life cycle of osteoblastic cells from the recruitment of osteoblast progenitors to their mineralization and apoptosis (Robey et al., 1987; Hock et al., 1990;
Yamaguchi et al., 1996; Hay et al., 2001). In addition, they can augment the production of VEGF mRNA in osteoblastic linage cells in vitro (Pertovaara et al., 1994; Deckers et al., 2000). According to other studies, VEGF, as a powerful angiogenic inducer can also regulate osteoblast activity by recruiting mesenchymal progenitor cells and stimulating their differentiation (Mayr-Wohlfart et al., 2002; Street et al., 2002). Also, some in vivo studies indicated that the expression level of these three growth factors was up-regulated during bone fracture healing and distraction osteogenesis (Pufe et al., 2002; Wildemann et al., 2004; Marukawa et al., 2006). Moreover, their local administration can lead to significantly increased bone formation (Ueda et al., 2002; Geiger et al., 2005; Yamamoto et al., 2006).

Studies of the spatial and temporal expression patterns of several growth factors and the close correlation of their expression with local histological events showed that they play important roles in the healing process of tooth extraction sockets (Lalani et al., 2003). Hence, in this study we tested the hypothesis that simvastatin augments new bone formation in tooth extraction sockets partly by regulating the expression of TGF- $\beta 1$, BMP-2 and VEGF.

\section{Materials and methods}

\section{Animals and experimental protocol}

Forty-eight male Wistar rats (7-8 weeks old) with an average body weight of $(180 \pm 5) \mathrm{g}$ were used. All animals were bred in Jilin University Laboratory Animal Center and housed under similar conditions $\left(22^{\circ} \mathrm{C}\right.$ room temperature, $40 \%$ humidity and 12 hours daylight cycle). The rats were fed $a d$ libitum with a standard laboratory diet and water. All procedures followed the guidelines of the Jilin University for Animal Research. The experimental protocols were approved by the local ethics committee.

The animals were randomly divided into an experimental group and a control group. The methods for the preparation of simvastatin (Merck, USA) -PLGA scaffold and lower incisor extraction have been described elsewhere (Wu et al., 2008). Briefly, 
each rat's right incisor was carefully extracted under deep anesthesia with ketamine hydrochloride. Then, the simvastatin-PLGA and PLGA scaffolds were implanted into the tooth sockets of the experimental group and the control group, respectively. The sockets were closed by suturing the gingiva together. All the rats were given penicillin continuously for 3 days after the extraction. The health status and healing process of the sockets were monitored periodically after the surgical procedure.

The rats were killed at five days, one week, two weeks or four weeks after the operation. All the rats were perfused through the ascending aorta with $0.9 \%$ saline and $4 \%$ paraformaldehyde solution (pH 7.4) under deep anesthesia. After surgical removal, the whole right mandible was post-fixed in the same fixative for 24 hours at $4^{\circ} \mathrm{C}$, followed by decalcification with $10 \%$ EDTA solution $(\mathrm{pH}$ 7.4) for four weeks. The tissue blocks including the first molar and underlying mandibular bone were removed and embedded in paraffin. Serial cross sections at $5 \mathrm{~mm}$ were obtained and mounted on APS-coated glass slides.

\section{In situ hybridization}

In situ hybridization was performed according to the method of Hajjar and Santos with minor modifications (Hajjar et al., 2003). Briefly, sections were deparaffinized in xylene, washed twice in absolute ethanol, and then treated with $3 \% \mathrm{H}_{2} \mathrm{O}_{2}$ in absolute methanol for inactivation of endogenous peroxidase. After hydration through graded ethanol, the sections were treated with $20 \mu \mathrm{g} / \mathrm{mL}$ of proteinase K (Roche, Germany) for 10 minutes, postfixed in $4 \%$ paraformaldehyde, and incubated in pre-hybridization buffer ( $50 \%$ deionized formamide, $0.5 \mathrm{mg} / \mathrm{mL}$ Salmon sperm DNA, $5 \times \mathrm{SSC}, 5 \times$ Denhardt's solution, in diethylpyrocarbonate-treated water) at $37^{\circ} \mathrm{C}$ for 1 hour to prevent excessive background staining. $1 \mu \mathrm{g} / \mathrm{mL}$ of digoxigenin-labeled oligonucleotide-TGF $\beta 1$ antisense probe (5'-CTCA GGCGTATCAGTGGGGGTCAGCAGCCGGTTA CCAAGGTAACGCCA-3'), BMP-2 antisense probe (5'-CGTCCTTGCTGGGGGTGGGTCTCTGCTT CAGGCCAAACATGCTGAGCA-3') or VEGF antisense probe (5'-AGGAACATTTACACGTCT GCGGATCTTGGACAAACAAATGCTTTCTCC -3') (HaoYang Biotech Co., China) was diluted in hybridization buffer $(50 \%$ deionized formamide, $10 \%$ dextran sulfate, $0.5 \mathrm{mg} / \mathrm{mL}$ Salmon sperm DNA, $5 \times$ SSC, $5 \times$ Denhardt's solution, in diethylpyrocarbonate-treated water) and added to the treated specimens. The sense probe (JingYang Biotech Co., China) and the omission of the antisense probe were both used as negative controls. The hybridization temperature was $37^{\circ} \mathrm{C}$, and the incubation time was 20 hours. After hybridization, the slides were rinsed with SSC solutions $(2 \times, 2 \times, 1 \times$ and $0.5 \times)$ at $37^{\circ} \mathrm{C}$ for 15 minutes. They were then incubated with anti-digoxingenin-peroxidase, Fab fragments (Roche, Germany) at room temperature for 1.5 hours and stained with 3,3'-diaminobenzidine (DAB; Sigma, USA) as chromogen. The sections were counterstained with haematoxylin and observed using an optical microscope.

\section{Quantitative and statistical analysis}

Sections were first examined at $\times 4$ magnification and the long and short axes of the tooth extraction socket were measured. Four different areas were identified at the intersection between the long or short axes and the wall of the alveolar bone (Figure 1). Once the area of interest was determined, pictures were obtained using a digital camera (Sony, Japan) at a magnification of $\times 200$. Four

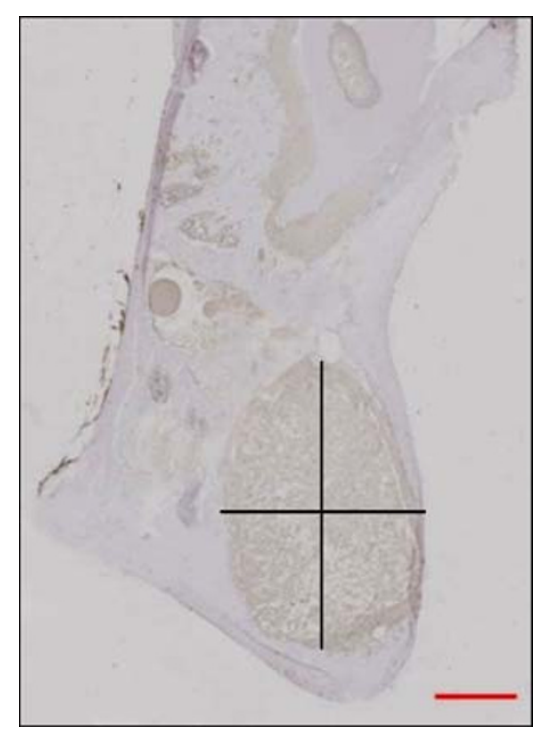

Figure 1 The long and short axes of each tooth extraction socket were determined

Four different measurement frames were positioned at the intersection between the long or short axes and the wall of the alveolar bone for each section. Scale bar $=500 \mu \mathrm{m}$. 
measurement frames each of $300 \mu \mathrm{m} \times 200 \mu \mathrm{m}$ along the long or short axis were located tangent to the wall of the tooth socket and towards to the center of the extraction socket (Figure 2). The number of cells with positive staining of TGF- $\beta 1$, BMP-2 and VEGF (more than 60 pixels) was counted in the measurement frames using Image Pro-Plus (Media Cybernetics, Silver Spring, USA). The average of the positive cell number in four measurement frames on each slide was used in this study.

The data was processed using SPSS 12.0 (SPSS, USA) for paired $t$-tests. Thirty sections from 10 subjects were selected randomly and measured on two separate occasions about one month apart for method error analysis. The error of measurement was calculated using Dahlberg's formula (Dahlberg, 1940):

$$
M e=\sqrt{\frac{\sum d^{2}}{2 n}}
$$
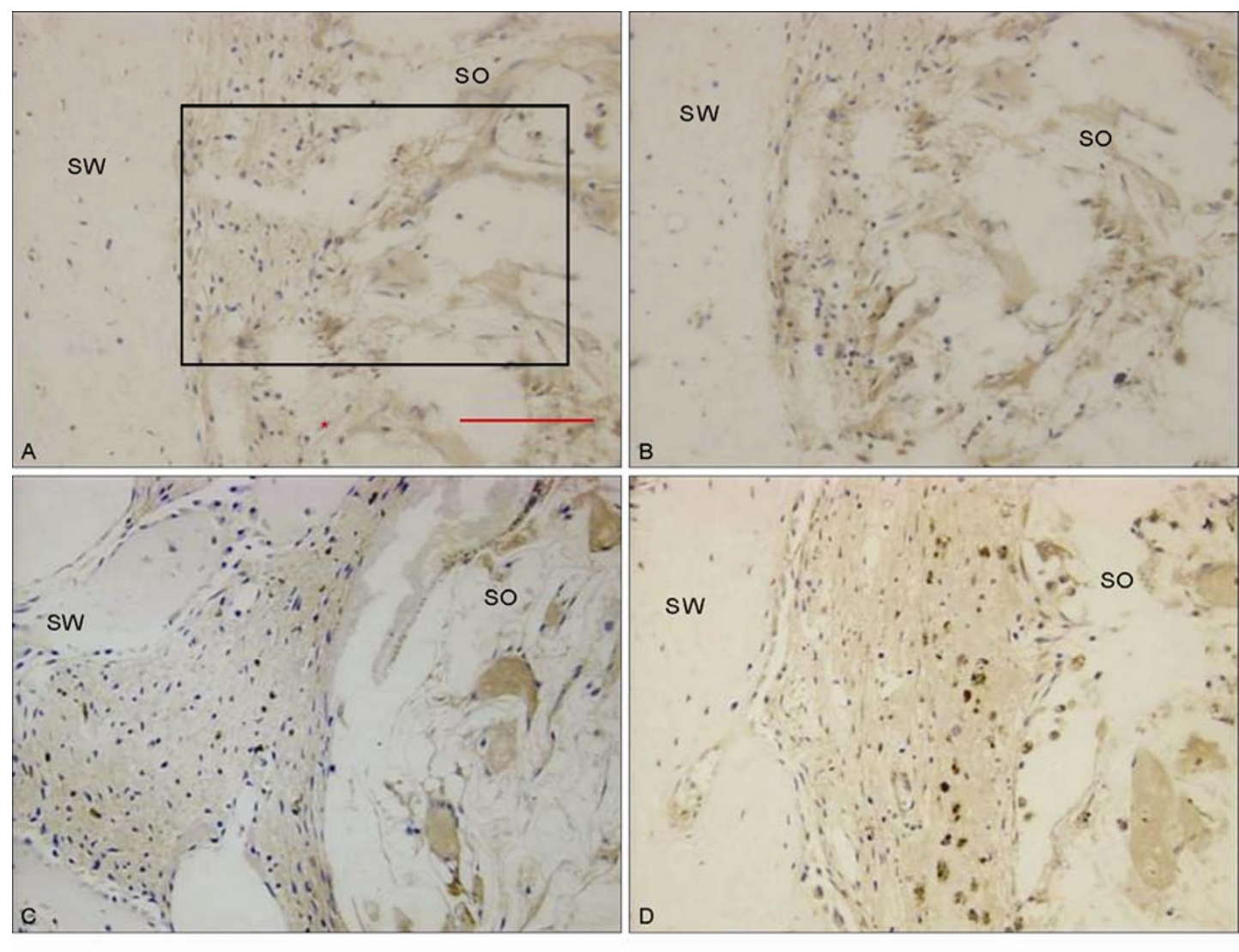

Control group in which $d$ represents the difference between two registrations and $n$ is the number of duplicate registrations. Hypothesis testing indicated no significant difference among the registrations for TGF- $\beta_{1}$, BMP- 2 and VEGF.

\section{Results}

Brown signals of TGF- $\beta_{1}$, BMP-2 mRNA were localized mainly in the cytoplasm of fusiform stroma cells between the wall of the alveolar bone and scaffold material in the early stage of the experiment and later also in the osteoblastic cells around the new bone. Occasionally the osteoclast showed positive staining in the later stages of the experiment. Positive signal of VEGF mRNA was recognized in the cytoplasm of fusiform stroma cells, osteoblastic cells and endothelial cells (Figures 2, 3, 4).

Figure 2 The expression of TGF- $\beta 1$ mRNA

(A) and (B): show the expression of TGF- $\beta 1$ mRNA after one week. (C) and (D): show the expression of TGF- $\beta 1$ mRNA after two weeks. The measure frame with a size of $300 \mu \mathrm{m} \times 200 \mu \mathrm{m}$ is shown in Figure 2A.

SW: socket wall; SO: socket; asterisk: carrier. scale bar $=100 \mu \mathrm{m} .(200 \times)$. 


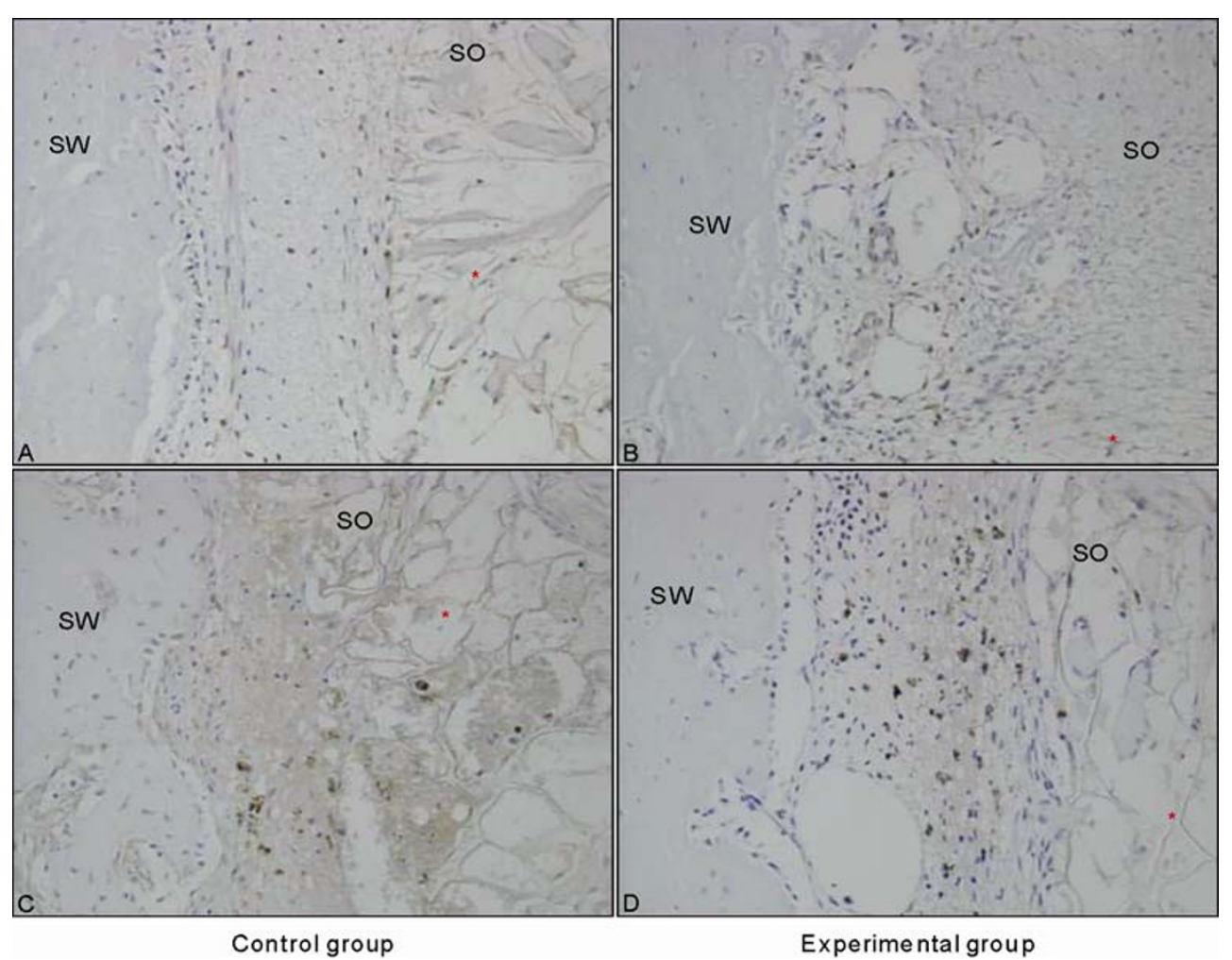

Figure 3 The expression of BMP-2 mRNA

(A) and (B): show the expression of BMP-2 mRNA after one week. (C) and (D): show the expression of BMP-2 mRNA after two weeks. SW: socket wall; SO: socket; asterisk: carrier. $(200 \times)$.



Figure 4 The expression of VEGF mRNA

(A) and (B): show the expression of VEGF mRNA after one week. (C) and (D): show the expression of VEGF mRNA after two weeks. SW: socket wall; SO: socket; asterisk: carrier. $(200 \times)$. 




Figure 5 The change in the expression of TGF- $\beta 1$ mRNA during the experiment

$*: P<0.05 ; * *: P<0.01$.

\section{Quantitative analysis of TGF- $\beta_{1}$ mRNA expre- ssion}

Very weak signal of TGF- $\beta_{1}$ could be detected in both experimental and control groups after five days. However, the positive signal was too weak to be analyzed statistically at this time point. After one week, the expression of TGF- $\beta_{1}$ mRNA could be recognized in the control and experimental groups. The number of cells with positive signals in the experimental group was significantly higher than that in the control group after one, two and four weeks. The number of positive cells peaked after two weeks and then decreased after four weeks in both the experimental and control groups (Figure 5).

\section{Quantitative analysis of BMP-2 mRNA expre- ssion}

No positive signal could be detected after five days in both the experimental and the control groups. From one week onwards, the number of positive cells in the experimental group was significantly higher than that in control group, with both groups peaking after two weeks (Figure 6).

\section{Quantitative analysis of VEGF mRNA expre- ssion}

Likewise, no positive signal for VEGF could be observed after five days in both the experimental and control groups. After one and two weeks, the number of positive cells in the experimental group

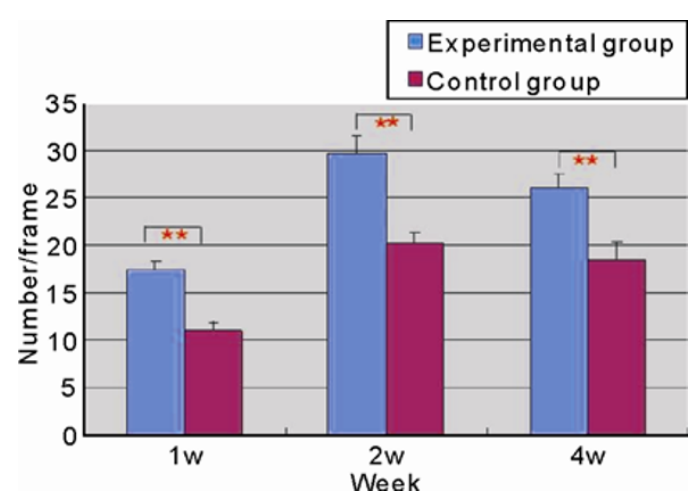

Figure 6 The change in the expression of BMP-2 mRNA during the experiment

$*: P<0.05 ; * *: P<0.01$

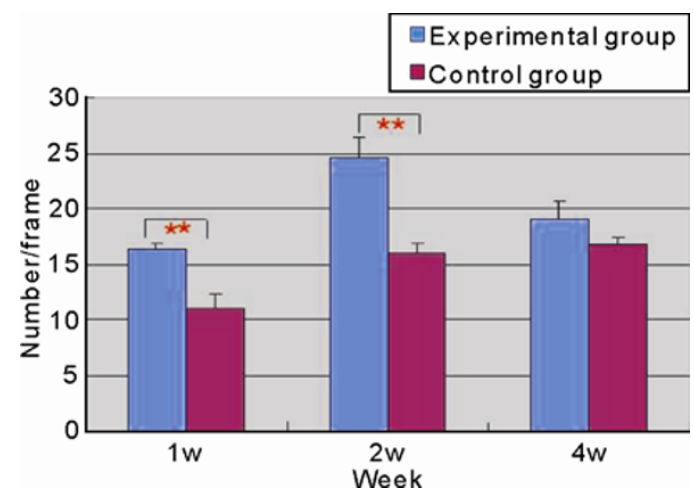

Figure 7 The change in the expression of VEGF mRNA during the experiment

$*: P<0.05 ; * *: P<0.01$

was significantly higher than that in the control group but it decreased thereafter. There was no significant difference in the number of positive cells between the experimental and control groups after four weeks (Figure 7).

\section{Discussion}

Previous studies confirmed that the healing process of tooth extraction sockets involves the chemotaxis of mesenchymal cells, their proliferation and differentiation into osteoblastic cells and the production and mineralization of extracellular matrix (ECM) by osteoblasts (Hollinger and Wong, 1996). It has been found that these critical cellular events are tightly regulated by appropriate signal molecules, such as growth factors and cytokines (Lalani et al., 2003). Some growth factors, such as TGF- $\beta_{1}$, BMP-2 and VEGF, are signaling proteins secreted by cells recruited to 
the tooth extraction socket which control osteogenesis and angiogenesis by autocrine and paracrine in the local area. Owing to the competent ability of these growth factors in promoting bone formation, many studies focused on screening chemical compounds or medicines which can induce increased expression of these proteins (Mundy et al., 1999). In our previous studies, we found that local administration of simvastatin carried by PLGA can significantly increase new bone formation in the tooth extraction socket without obvious side effects on the healing process (Wu et al., 2008). In the present study, we investigated the expression level of TGF- $\beta_{1}$, BMP-2 and VEGF mRNA, trying to improve our understanding of the mechanisms of osteogenesis and angiogenesis induced by simvastatin in tooth extraction animal models.

Although the signal was very weak, the expression of TGF- $\beta_{1}$ was detected from five days. This was earlier than the expression of BMP-2 and VEGF. TGF- $\beta_{1}$ has been shown to expand the pool of osteoprogenitors by inducing chemotaxis and stimulating proliferation (Harris et al., 1994). In addition, TGF- $\beta_{1}$ can induce the expression of ECM proteins and osteoblastic differentiation markers (ALP) to regulate the early differentiation of osteoprogenitors by up-regulating the expression of Runx2, a DNA-binding transcription factor specific for osteogenic lineage cells (Robey et al., 1987; Hock et al., 1990; Lee et al., 2000). However, TGF- $\beta_{1}$ is also responsible for increasing the expression of VEGF which can promote bone formation and repair by angiogenesis and vasculogenesis (Pertovaara et al., 1994; Mayr-Wohlfart et al., 2002; Street et al., 2002). Therefore, our finding supports these studies, because the earlier expression of TGF- $\beta_{1}$ is critical for regulating the early stages of cellular events and for stimulating the production of essential signaling proteins in wound healing. After one week, a higher expression level of TGF- $\beta_{1}$, BMP-2 and VEGF mRNA was detected in the experimental group compared with that in the control group, with the peak expression level observed after two weeks for both experimental and control groups. This result suggests that simvastatin released from the scaffold can increase the expression level of these three osteoinductive growth factors and, therefore, promote the later new bone formation in the tooth socket. Their temporal expression paralleled results from our previous histological study in which we showed that extensive new bone formation in tooth extraction sockets was observed two and four weeks after extraction in both experimental and control groups (Wu et al., 2008). The beginning of expression of these three factors after one week preceded the appearance of newly formed bone after two weeks. Their peak expression level occurred two weeks earlier than the most extensive bone formation at four weeks, as time is required for the recruitment of mesenchymal cells and the subsequent cascade of events to initiate new bone formation. Although some studies showed that statins down-regulate TGF- $\beta_{1}$ expression in some pathological situations, statins were found to increase the expression of TGF- $\beta_{1}$ in macrophages and monocytes (Porreca et al., 2002; Li et al., 2004; Baccante et al., 2004; Song et al., 2008). The effect of statins on TGF- $\beta_{1}$ expression might depend on the experimental conditions and cell types. However, the effect of simvastatin on expression level of TGF- $\beta_{1}$ in bone has never been reported. Because both TGF- $\beta_{1}$ and BMP-2 belong to the TGF- $\beta$ superfamily, simvastatin may upregulate the expression of TGF- $\beta_{1}$ in a way similar to the up-regulation of BMP-2. The up-regulation of BMP-2 and VEGF mRNA is in agreement with previous studies. Since the osteoinductive ability of simvastatin was first described by Mundy et al., many other studies have shown that simvastatin markedly augments not only the expression of BMP-2 and VEGF, but also that of some ECM molecules such as type I collagen, ALP, bone sialoprotein, and osteocalcin in osteoblastic cell lines (Maeda et al., 2003; Maeda et al., 2004). Another study by Wong et al., indicated that simvastatin triggers the early expression of BMP-2 and VEGF after one day in bone defects (Wong and Rabie, 2005). However, this early expression pattern was not observed in this study. This discrepancy can be ascribed to the difference in observation time points. After four weeks, new bone formation was almost completed, especially in the measurement frame on the boundary area between the scaffold and the alveolar bone where the new bone formation first began. It has been reported that the healing process of tooth extraction is faster in rats than in humans (Pietrokovski and 
Massler, 1967). Therefore, the expression level of these three factors was down-regulated compared with that at two weeks owing to decreased osteogenic activity.

\section{Conclusion}

In conclusion, local administration of simvastatin significantly increased the expression level of TGF- $\beta_{1}$, BMP-2 and VEGF mRNA one week after tooth extraction and the temporal upregulation of these factors correlated well with the temporal increase in new bone formation. The up-regulation of TGF- $\beta_{1}$ mRNA needs conformation in in vitro studies and the underlying mechanism needs further investigation in the future.

\section{Acknowledgements}

This study was supported by grants from the National Nature Science foundation of China (Grant Nos. 30872912 and 30830108).

\section{References}

Baccante G, Mincione G, Di Marcantonio, Piccirelli A, Cuccurullo F, Porreca E (2004). Pravastatin up-regulates transforming growth factor-beta 1 in THP-1 human macrophages: effect on scavenger receptor class A expression. Biochem Biophys Res Commun, 314(3): 704-710.

Dahlberg G (1940). Statistical Methods for Medical and Biological Student. London: Gorge Allen \& Unwin LTD. pp.122-132.

Davignon J (2004). Beneficial cardiovascular pleiotropic effects of statins. Circulation, 109(23 Suppl 1): III3943.

Deckers MM, Karperien M, van der Bent C, Yamashita T, Papapoulos SE, Lowik CW (2000). Expression of vascular endothelial growth factors and their receptors during osteoblast differentiation. Endocrinology, 141 (5): 1667-1674.

Geiger F, Bertram H, Berger I, Lorenz H, Wall O, Eckhardt C, et al. (2005). Vascular endothelial growth factor gene-activated matrix (VEGF165-GAM) enhances osteogenesis and angiogenesis in large segmental bone defects. J Bone Miner Res, 20(11): 2028-2035.

Hajjar D, Santos MF, Kimura ET (2003). Propulsive appliance stimulates the synthesis of insulin-like growth factors I and II in the mandibular condylar cartilage of young rats. Arch Oral Biol, 48(9): 635-642.

Harris SE, Bonewald LF, Harris MA, Sabatini M, Dallas S, Feng JQ, et al. (1994). Effects of transforming growth factor beta on bone nodule formation and expression of bonemorphogenetic protein 2, osteocalcin, osteopontin, alkaline phosphatase, and type I collagen mRNA in long-term cultures of fetal rat calvarial osteoblasts. $J$ Bone Miner Res, 9(6): 855-863

Hay E, Lemonnier J, Fromigue O, Marie PJ (2001). Bone morphogenetic protein-2 promotes osteoblast apoptosis through a Smad-independent, protein kinase C-dependent signaling pathway. J Biol Chem, 276(31): 29028-29036.

Hock JM, Canalis E, Centrella M (1990). Transforming growth factor- $\beta$ stimulates bone matrix apposition and bone cell replication in cultured fetal rat calvariae. Endocrinology, 126(1): 421-426.

Hollinger J, Wong ME (1996). The integrated processes of hard tissue regeneration with special emphasis on fracture healing. Oral Surg Oral Med Oral Pathol Oral Radiol Endod, 82(6): 594-606.

Lalani Z, Wong M, Brey EM, Mikos AG, Duke PJ (2003). Spatial and temporal localization of transforming growth factor-beta1, bone morphogenetic protein-2, and platelet-derived growth factor-A in healing tooth extraction sockets in a rabbit model. J Oral Maxillofac Surg, 61(9): 1061-72.

Lee KS, Kim HJ, Li QL, Chi XZ, Ueta C, Komori T, et al. (2000). Runx2 is a common target of transforming growth factor beta 1 and bone morphogenetic protein 2, and cooperation between Runx 2 and Smad5 induces osteoblast-specific gene expression in the pluripotent mesenchymal precursor cell line C2C12. Mol Cell Biol, 20(23): 8783-8792.

Li C, Yang CW, Park JH, Lim SW, Sun BK, Jung JY, et al. (2004). Pravastatin treatment attenuates interstitial inflammation and fibrosis in a rat model of chronic cyclosporine-induced nephropathy. Am J Physiol Renal Physiol, 286(1): F46-57.

Maeda T, Kawane T, Horiuchi N (2003). Statins augment vascular endothelial growth factor expression in osteoblastic cells via inhibition of protein prenylation. Endocrinology, 144(2): 681-692.

Maeda T, Matsunuma A, Kurahashi I, Yanagawa T, Yoshida H, Horiuchi N (2004). Induction of osteoblast differentiation indices by statins in MC3T3-E1 cells. $J$ Cell Biochem, 92(3): 458-471.

Marukawa K, Ueki K, Alam S, Shimada M, Nakagawa K, Yamamoto E (2006). Expression of bone morphogenetic protein-2 and proliferating cell nuclear antigen 
during distraction osteogenesis in the mandible in rabbits. Br J Oral Maxillofac Surg, 44(2): 141-145.

Mayr-Wohlfart U, Waltenberger J, Hausser H, Kessler S, Gunther KP, Dehio C, et al. (2002). Vascular endothelial growth factor stimulates chemotactic migration of primary human osteoblasts. Bone, 30(3): 472-477.

Mundy G, Garrett R, Harris S, Chan J, Chen D, Rossini G, et al. (1999). Stimulation of bone formation in vitro and in rodents by statins. Science, 286(5446): 19461949.

Ozeç I, Kiliç E, Gümüş C, Göze F (2007). Effect of local simvastatin application on mandibular defects. $J$ Craniofac Surg, 18(3): 546-550.

Pertovaara L, Kaipainen A, Mustonen T, Orpana A, Ferrara N, Saksela O, et al. (1994). Vascular endothelial growth factor is induced in response to transforming growth factor- $\beta$ in fibroblastic and epithelial cells. $J$ Biol Chem, 269(9): 6271-6274.

Pietrokovski J, Massler M (1967). Ridge Remodeling after tooth extraction in Rats. J Dent Res, 46(1): 222-231.

Porreca E, Di Febbo C, Baccante G, Di Nisio M, Cuccurullo $F$ (2002). Increased transforming growth factorbeta (1) circulating levels and production in human monocytes after 3-hydroxy-3-methyl-glutaryl-coenzyme a reductase inhibition with pravastatin. $J$ Am Coll Cardiol, 39(11): 1752-1757.

Pufe T, Wildemann B, Petersen W, Mentlein R, Raschke M, Schmidmaier G (2002). Quantitative measurement of the splice variants 120 and 164 of the angiogenic peptide vascular endothelial growth factor in the time flow of fracture healing: a study in the rat. Cell Tissue Res, 309(3): 387-392.

Robey PG, Young MF, Flanders KC, Roche NS, Kondaiah $\mathrm{P}$, Reddi AH, et al. (1987). Osteoblasts synthesize and respond to transforming growth factor-type $\beta$ (TGF- $\beta$ ) in vitro. J Cell Biol, 105(1): 457-463.

Ruiz-Gaspa S, Nogues X, Enjuanes A, Monllau JC, Blanch J, Carreras R, et al. (2007). Simvastatin and atorvastatin enhance gene expression of collagen type 1 and osteocalcin in primary human osteoblasts and MG-63 cultures. J Cell Biochem, 101(6): 1430-1438.

Song CY, Kim BC, Lee HS (2008). Lovastatin inhibits oxidized low-density lipoprotein-induced plasminogen activator inhibitor and transforming growth factorbetal expression via a decrease in Ras/extracellular signal-regulated kinase activity in mesangial cells. Transl Res, 151(1): 27-35.

Staal A, Frith JC, French MH, Swartz J, Gungor T, Harrity TW, et al. (2003). The ability of the statins to inhibit bone resorption is directly related to their inhibitory effect on HMG-CoA reductase activity. $J$ Bone Miner Res, 18(1): 88-96.

Street J, Bao M, deGuzman L, Bunting S, Peale FV, Ferrara N, et al. (2002). Vascular endothelial growth factor stimulates bone repair by promoting angiogenesis and bone turnover. Proc Natl Acad Sci USA, 99(15): 9656-9661.

Ueda H, Hong L, Yamamoto M, Shigeno K, Inoue M, Toba $\mathrm{T}$, et al. (2002). Use of collagen sponge incorporating transforming growth factor-beta1 to promote bone repair in skull defects in rabbits. Biomaterials, 23(4): 1003-1010.

Wildemann B, Schmidmaier G, Brenner N, Hüning M, Stange R, Haas NP, et al. (2004). Quantification, localization, and expression of IGF- I and TGF-beta 1 during growth factor-stimulated fracture healing. Calcif Tissue Int, 74(4): 388-397.

Wong RW, Rabie AB (2005). Histologic and ultrastructural study on statin graft in rabbit skulls. J Oral Maxillofac Surg, 63(10): 1515-1521.

Wu Z, Liu C, Zang G, Sun H (2008). The effect of simvastatin on remodelling of the alveolar bone following tooth extraction. Int J Oral Maxillofac Surg, 37(2): 170-176.

Yamaguchi A, Ishizuya T, Kintou N, Wada Y, Katagiri T, Wozney JM, et al. (1996). Effects of BMP-2, BMP-4 and BMP-6 on osteoblastic differentiation of bone marrow-derived stromal cell lines, ST2 and MC3T3G2/PA6. Biochem Biophys Res Commun, 220(2): 366371.

Yamamoto M, Takahashi Y, Tabata Y (2006). Enhanced bone regeneration at a segmental bone defect by controlled release of bone morphogenetic protein-2 from a biodegradable hydrogel. Tissue Eng, 12(5): 1305-1311.

*Corresponding author: Hong-chen Sun

Address: Department of Oral Pathology, School of Stomatology, Jilin University, 418 Ziqiang Street, Nanguan District, Changchun 130041, China

Tel: 8643188796012 E-mail: hcsun@mail.jlu.edu.cn 